大型試験片を用いた柱状結晶水の破壊じん性の検討

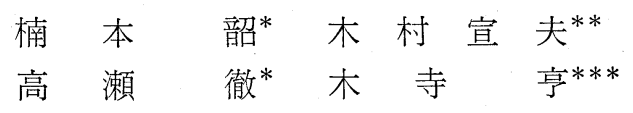

\title{
Study of Fracture Toughness of Columnar \\ Grained Ice Using Large Specimens
}

by

\author{
Sho Kusumoto*, Nobuo Kimura**, Tooru TAKase* \\ and Tohru KIDERA***
}

The effects of loading rate and specimen size on the fracture toughness $K_{\mathrm{Ic}}$ of columnar grained ice have been investigated at $-10^{\circ} \mathrm{C}$. Notched bend specimens with the section size of $50 \times 50 \mathrm{~mm}$ (medium size specimen) and $200 \times 50 \mathrm{~mm}$ (large size specimen) were used. The notch of specimen was made using a thin razor blade embedded in the mold. Several tests were carried out at each test condition, and probabilistic nature of fracture toghness was also investigated.

The results obtained are as follows.

(1) The value of $K_{\mathrm{I} c}$ decreased as $\dot{K}_{\mathrm{I}}$ increased, and there was a transition in the range of $\dot{K}_{\mathrm{I}}$ $\doteqdot 10-100 \mathrm{kPam}^{1 / 2} / \mathrm{s}$. The value of $K_{\mathrm{Ic}}$ was not substantially affected by $\dot{K}_{\mathrm{I}}$ in the high $\dot{K}_{\mathrm{I}}$ region beyond the transition.

(2) Scatter of $K_{\text {Ic }}$ for the large size specimens was considerably small compared with that for the medium size specimens.

(3) The minimum value of $K_{\mathrm{I} c}$ was not affected by the specimen size in the low $\dot{K}_{\mathrm{I}}$ range. However, in the high $\dot{K}_{\mathrm{I}}$ range, the minimum value of $K_{\mathrm{Ic}}$ of a large specimen showed a little higher value than that of a medium specimen.

(4) The size effect was analyzed from the view point of the "weakest link theory". It was observed that the experimental data did not agree with the theoretical prediction in the range of low values of $K_{\mathrm{Ic}}$.

(5) The relation between $\dot{K}_{\mathrm{I}}$ and $K_{\mathrm{Ic}}$ was compared with other experimental data on a similar kind of ice. Considerable difference in $K_{\mathrm{Ic}}$, especially in the low loading rate range, was observed. The reason is not yet clear, and more studies are needed.

キー・ワード: 破壊じん性, 負荷速度, 寸法効果, 水

1 緒

氷の破壊じん性值 $K_{\mathrm{I} c}^{* 1}$ に対する負荷速度の影響に ついては,これまでにる幾つかの報告がある。筆者ら もさきに平滑部断面寸法 $25 \times 25 \mathrm{~mm}$ の小型試験片打 よび $50 \times 50 \mathrm{~mm}$ の中型試験片を用いて負荷速度 $\dot{K_{\mathrm{I}}} \fallingdotseq$ 1 $2000 \mathrm{kPam}^{1 / 2} / \mathrm{s}$ のかなり広い範囲にわたって, 三点 曲げ試験によって $K_{\mathrm{I} c}$ を求める実験を行った. その結 果, $\dot{K}_{\mathrm{I}} \fallingdotseq 20 \sim 100 \mathrm{kPam}^{1 / 2} / \mathrm{s}$ 付近に $K_{\mathrm{I}_{c}}$ の值が急変す る遷移領域があり, 実験の範囲では, 遷移領域よりも 高い $\dot{K}_{\mathrm{I}}$ の範囲で $K_{\mathrm{I} c}$ に対する $\dot{K}_{\mathrm{I}}$ の影響が少ない ことを見出した．また，中型試験片の $K_{\mathrm{Ic}}$ のばらつき が小型試験片にくらべて少ないこと, 特よびばらつき
の下限は小型試験片にくらべて幾分高めであるが，注 涪同じレベルであることを述べた。

本報では前報より幾分広い $\dot{K}_{\mathrm{I}} \fallingdotseq 0.8 \sim 5000 \mathrm{kPam}^{1 / 2}$ / S の範囲内で上記寸法の中型試験片の他に平滑部断面 寸法 $200 \times 50 \mathrm{~mm}$ の大型試験片を用いて行った実験結 果について述べる。な报，本報の実験に用いた氷は前 報と異なって，後述の方法で作った多結晶柱状水であ る. 多結晶柱状氷を用いた理由は結晶粒子径が制御し やすいこと，および従来の他の研究例のほとんどがこ の種の氷を用いていて，結果が比較しやすいためであ る.

\footnotetext{
$†$ 本報を「氷の破壊じん性に及ぼす負荷速度の影響（第 2 報)」(Effect of Loading Rate on Fracture Toughness of Ice, II) とする. 原稿受理 昭和60年11月 2 日 Received Nov.2, 1985

* 正会員 長崎大学工学部 長崎市文教町, Faculty of Engineering, Nagasaki University, Bunkyo-machi, Nagasaki

** 正会員 (株)アドバンス開発研究所 府中市緑町, Advance Research and Development Co. Ltd., Midori-machi, Fuchu

*** 長崎大学工学部 (現在, 菱電エンジニアリング(株)), Faculty of Engineering, Nagasaki University, Bunkyo-machi, Nagasaki

*1 前報5)でも述べたように，高負荷で破壊した場合，小規模降伏の条件が満足されないケースも生じているのではないかと思われるが，便宜的に線 形破壤力学の応力拡大係数 $K_{\mathrm{I}}$ の計算式によって, 破断荷重から求めた値を用いている.
} 


\section{2 畜験方法}

\section{$2 \cdot 1$ 試験片}

多結晶柱状氷は従来報告されている方法にならって 製作した。すなわち、 $-10^{\circ} \mathrm{C}$ の低温室内で市販の水か き器で氷を削り，やはり市販のふるいによって粒径 2 $\mathrm{mm}$ 以下の水だけを集めて種水とする。これを一学 $-10^{\circ} \mathrm{C}$ に泠却したアクリル製の試験片製造用枠の底面に，お よそ $5 \mathrm{~mm}$ 程度の愿さになるをで散布する。つぎに， 霧吹さによって $0^{\circ} \mathrm{C}$ 蒸留水を種水が透明になるまで 一様に散布して完全に凍結するまで放置する。そのあ と, $0^{\circ} \mathrm{C}$ の蒸留水を注入しフリーザ内に設置し，底面 から上向きに氷を成長させ，氮泡の少ない透明な水を 得た. 試験片の切久きは次の方法で作った.すなわち, 厚さ $0.1 \mathrm{~mm}$, 先端角度 $11^{\circ}$ のカミンリ刃をあらかじ めアクリル製型の切欠き相当位置に装着し，これを試 験片成型後に技き取って切欠きとした，切欠きの深さ は中型・大型試験片ともに $20 \mathrm{~mm}$ とした。大型試験 片の場合は刃の拻き出しが難しいので，これを容易に 寸る目的で，为先 $5 \mathrm{~mm}$ を残して网の両面にそれぞれ 厚さ $0.4 \mathrm{~mm}$ のビニルテープを貼ったものを用いた。 したがって，こ礼を抜き出した步とには幅 $0.9 \mathrm{~mm} の$ 矩形切欠きの先端に深さ $5 \mathrm{~mm}$ の冈形切欠きができて いる。な和，刐を抜き取る際には無理がかからない上 らに, 刃の片面 (大型試験片では片側のビニルテープ の面）に沿って薄刃のノコギリで試験片に，深さ10 $12 \mathrm{~mm}$ の切込名怘つけてから抜き取った。このため， この部分は切欠きの輁幅が中型試験片では約 $0.8 \mathrm{~mm}$, 大型試験片では 1.5 1.7 mm となっている.

なお，刃の抜き取りは試験片の外形を成型後 $-10^{\circ} \mathrm{C}$ のケロシン中に一昼夜保存して成型後の残留応力を 除去した後に行った。試験片の偏光写真をFig.1 1 示した。Fig. 1 (a)は水平断面で, 凍結方向に莗直であ る. Fig. 1 (b)は垂直断面で, 凍結方向を含む断面であ る. 結晶の平均粒径は約 $5 \mathrm{~mm}$ であった. 中型試験片 寸法は厚さ $50 \mathrm{~mm} \times$ 高さ $50 \mathrm{~mm} \times$ 長さ $240 \mathrm{~mm}$, 大 型試験片寸法は $200 \mathrm{~mm} \times 50 \mathrm{~mm} \times 250 \mathrm{~mm}$ とした。

\section{$2 \cdot 2$ 多結晶柱状水の $\mathrm{C}$ 軸方位分布}

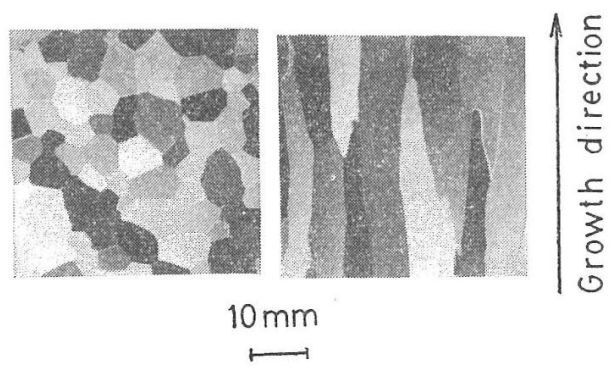

(a) Horizontally sliced (b) Vertically sliced

Fig. 1. Thin cross sections of columnar grained ice specimen.

氷結晶は六方晶系をなし，ミラー指数 (0001) 面が 基底面で，この面と垂直な方向にC 軸がある。得られ た試験片の結晶成長方向と氷の結晶主軸（C軸）の分 布との関係を知るために，樋口によるエッチピット法 を用いた，先の結果，今回用いた試験片は，成長方向 に対して 60〜90の間でランダムに，C軸方位を持つ 多結晶柱状氷で構成されていることがわかった。

\section{$2 \cdot 3$ 試験装置}

実験は $-10^{\circ} \mathrm{C}$ の低温室内で三点曲げ試験で行った、支 点間距離 $L$ と試験片高さ $B$ との比 $L / B$ は 4 として, 通常使われている応力拡大係数の式を用い, 破壊時の 最大荷重から破壞じん性值 $K_{\mathrm{I} c}$ 求めた。試験機ひ MTS 万能試験機（容量 : $10 \mathrm{t}$ ）を用いた. 荷重の検 出には長円形リングにひずみダージを貼ったもの（ば ね定数： $1.5 \times 10^{5} \mathrm{~N} / \mathrm{m}$ ) 艾主として用いた。

\section{$2 \cdot 4$ 破面観察}

破断面の観察は歯科用印象材を用いて作ったレプリ カたついて行った.

\section{3 実験結界と考察}

\section{$3 \cdot 1$ 破墁状況}

Fig. 2 (a)，(b)は先れぞれ中, 大型試験片のマクロレ プリカの例である。同図では省略したが，破面は負荷 速度が低い場合には凹队が目だっておら，また $K_{I_{e}}$ が 高い場合ほど，後述の丘陵型破面が現れる傾向がある。 図(a)で切欠き面に見られる段差は前述のカミソリ刃抜 き出し時のノコギリによる切込みの跡であり, 図(b)の

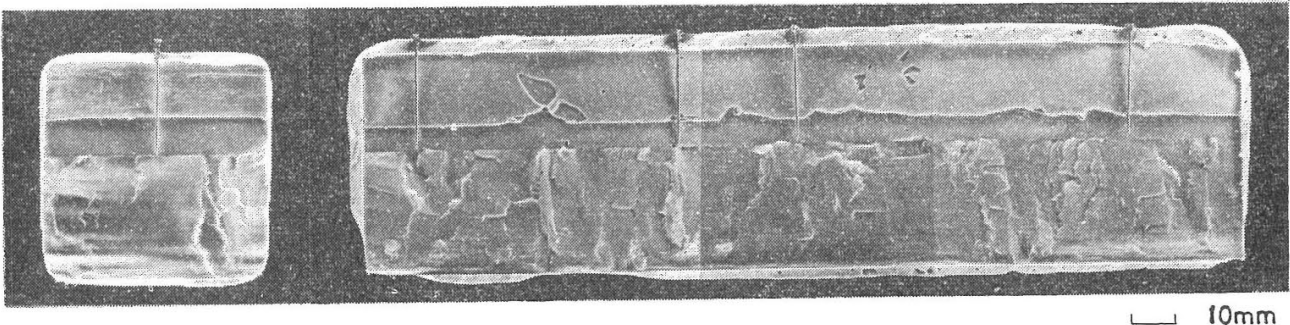

(a) Medium size specimen $\dot{K}_{\mathrm{I}}=4.29 \times$ $10^{3} \mathrm{kPam}^{1 / 2} / \mathrm{s}, K_{\mathrm{I} c}=87.3 \mathrm{kPam}^{1 / 2}$ (b) Large size specimen ${ }^{\text {ro }} \dot{K}_{\mathrm{I}}=2.06 \times 10^{3} \mathrm{kPam}^{1 / 2} / \mathrm{s}$, $K_{\mathrm{I} c}=83.4 \mathrm{kPam}^{1 / 2}$

Fig. 2. Examples of replica of fracture surface (pins indicate the start points of cracks). 
場合はカミソリ刃に貼ったビニルテープの跡である. このレプリカから色々な情報が得られるが，ここでは 曲げ試験中に観察されたことと併せて次記の二つの項 目について簡単に述べる.

（1）き裂の発生 Fig.2 (a)では切欠き底の一点か ら発生したき裂が，後出の特殊な場合を除いて，切欠 き底に沿って広がって行き，切欠き底全長に広がった のちに垂直方向に進行して行った状況が見られる.ま た，垂直方向への進行の途中時点でのき裂の前端位置 は結晶ごとに少しずつ差が見られる．同図(b)は大型試 験片の例である。(a), (b)を比較して最も大きな差は, 中型試験片のき裂の発生点が多くの場合 1 点なのに対 して，大型試験片のそれが複数個である点である。ま た，前報と和なじく多くのき裂は結晶境界から発生し た粒内き裂であった。

氷試験片は透明なので， $\dot{K}_{\mathrm{I}}$ が例壳ば数十 $\mathrm{kPam}^{1 / 2} / \mathrm{s}$ 以下といらような低負荷速度の場合には，よく注意す るとき裂の発生の目視が可能であって，破断荷重の65 〜 80\%の低い荷重ですでに部分的なき裂の発生が観測 される場合があった.これはポップインの 1 種である が，荷重-時間（負荷方法は変位制御）の記録上では 変化が検出でさなかった. 発生後のき裂の進展状況に ついては観察方法が難しいが，検討中である.

（2）丘陵型破面 低負荷速度でしかも比較的高い $K_{\mathrm{I} c}$ で破壊した試験片では，特徵のある破面を示す場 合がしばしば見受けられた．Fig. 3 はその典型的な例 のスケッチである．同図の切欠き底の中央付近で発生 したき裂が左方向では切欠き底を伝ぱせずに，丘陵面 を形成しながら矢印方向に進行している，また丘の頂 上から両側のふもと方向に広がったき裂のらち，片側 のき裂は切欠き面へと抜けている。丘の上部は極めて 滑らかであって，よほど注意しないと，ルーペを用い ても, き裂の進展の痕跡を見出すことが難しい場合が 多い。をた結晶境界も他の破面のように鋭い段差など

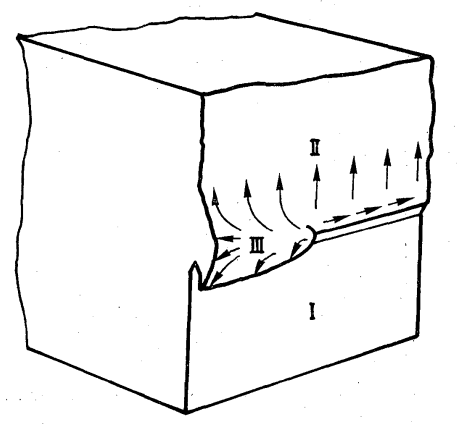

Fig. 3. Hill-shaped fracture surface (I : notch surface, II : fracture surface parallel to I, III hill-shaped fracture surface. Arrows indicate the directions of crack extension, schematic).
がなく平滑で，なだらかな起伏として認められる程度 である.なお，丘の高さは $\dot{K}_{\mathrm{I}}$ が低いほど，また， $K_{\mathrm{I} c}$ が高いほど大きい.このことから，筆者らはこの 破面がき裂先端の降伏域と密接な関係をもっているの ではないかとも考えているが，まだ，想像の域を出て いない.しかし，氷の降伏現象が複雑で，筆者らの知 る範囲では，き裂先端の降伏域の状況がクリープデー タを利用した計算による推定しかなされていない現在, 興味ある現象である.

\section{$3 \cdot 2 \quad \dot{K}_{\mathrm{I}}$ と $\boldsymbol{K}_{\mathrm{I} c}$ との関係}

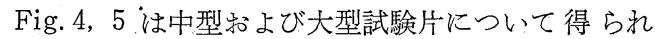
た $\dot{K}_{\mathrm{I}}$ と $K_{\mathrm{I} c}$ との関係を示す実験結果である。な拉, Fig. 5 には比較のために中型試験片のばらつきの範囲 を併記した。 これらの図から次のことが言える。

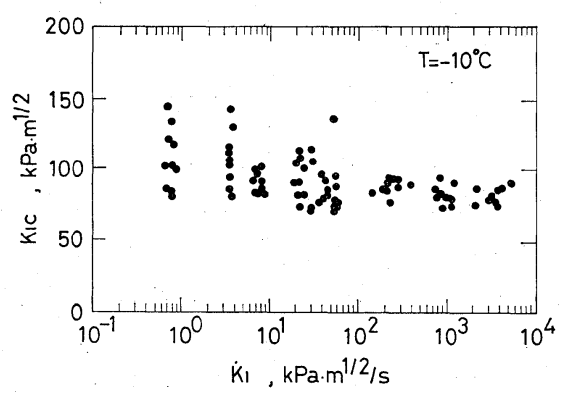

Fig. 4. Effect of loading rate on $K_{\mathbf{I} \boldsymbol{c}}$ values; medium size specimen.

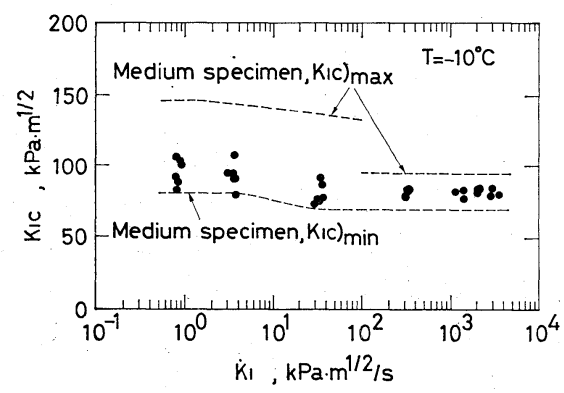

Fig. 5. Effect of loading rate on $K_{\mathrm{I} c}$ values; large size specimen.

(i) 中型, 大型両試験片とも $\dot{K}_{\mathrm{I}} \fallingdotseq 10 \sim 100 \mathrm{kPam}^{1 / 2} /$ $\mathrm{s}$ 付近に遷移領域があり，これを境として低負荷速度 側では $K_{\mathrm{I} c}$ が大, 高負荷速度では $K_{\mathrm{I} e}$ が小となって いる.なた，前報と同じく高負荷速度側で $K_{\mathrm{Ic}}$ に対す る $\dot{K}_{\mathrm{I}}$ の影響は小さい.

(ii) Fig. 5 に示す通り，大型試験片のばらつきは中 型試験片にくらべて約半分程度とかなり小さくなる. また，低負荷速度の領域に打いて，大型試験片の $K_{\mathrm{I} c}$ の最大值 $\left(107 \sim 108 \mathrm{kPam}^{1 / 2}\right)$ は中型試験片の最大值 (143〜146 $\mathrm{kPam}^{1 / 2}$ ) よりも低くなり，さらに両者の 下限值は約 $81 \mathrm{kPam}^{1 / 2}$ となってほぼ一致する。一 
方高負荷速度側では，大型試験片の最大值（う85 $\left.\mathrm{kPam}^{1 / 2}\right)$ は中型試験片 (92 96 $\left.\mathrm{kPam}^{1 / 2}\right)$ より 低下 するが， 最小值は大型試験片で $78 \sim 82 \mathrm{kPam}^{1 / 2}$ ， 中 型試験片で $74 \sim 78 \mathrm{kPam}^{1 / 2}$ で，大型試験片の方が幾 分大きい結果となっていた。

\section{$3 \cdot 3$ 最弱リンク説に基づく検討}

以上の結果からわかるように，破壞じん性値にはあ きらかに試験片寸法の影響がある。本報ではその影響 を最弱リンク説に従って統計的に検討した結果につい て述べる。これには内部に尔陥が分布した平滑試験片 の強度分布についての手法をき裂先端の線上に久陥が 分布している場合の強度問題に置き換えて適用すれば よい。

まず，切欠き底に存在し得る欠陥の破壊じん性值 $x$ の分布がワイブル分布であるとすると，分布関数 $F_{0}$ (x) は次式で表される.

$$
F_{0}(x)=1-\exp \left\{-\left(\frac{x-x_{0}}{\xi}\right)^{\varepsilon}\right\}
$$

ここで， $x_{0}$ は位置母数， $\xi$ は尺度母数， $\varepsilon$ は形状母 数である. また, 切欠き底の単位長さ当たりの久陥の 数を $\alpha$ とすると, 切欠さ先端部の長さ $B$ の間に存在す る欠陥数は $\alpha B$ である. そして， $x$ の母集団の中から 任意に選んだ $\alpha B$ 個の $x$ のうちの最小值の分布関数が 試験片の破壊じん性值 $K_{\mathrm{I}}$ の分布関数となる.この最 小值の分布関数は次式で与只られる.

$$
\begin{aligned}
F_{m}(x) & =1-\left\{1-F_{0}(x)\right\}^{m} \\
m & =\alpha B_{m} \\
F_{l}(x) & =1-\left\{1-F_{0}(x)\right\}^{l} \\
l & =\alpha B_{l}
\end{aligned}
$$

ここで, $F_{m}(x), F_{l}(x)$ は中，大型乞れぞれの個及の 試験片のき裂先端部の線上に並んでいる欠宿部の強度 の最小值の分布関数，すなわち，試験片の破壞じん性 值の分布関数であり, $B_{m}, B_{l}$ は中, 大型試験片のき 裂先端部の長さ, すなわら試験片の厚さである.

式(2)，(3)から $F_{0}(x)$ を消去すると，次式が得られ る.

$$
F_{l}(x)=1-\left\{1-F_{m}(x)\right\}^{B_{l} / B_{m}}
$$

ここで, 本報の場合は $B_{l} / B_{m}=4$ である.

式(4)は中, 大型試験片の $K_{\mathrm{Ic}}(\equiv x)$ の分布関数の換 算式である.

Fig. 6 には本報の実験結果を示してあるが，それぞ れ, $K_{\mathrm{I} c}$ に対する $\dot{K_{\mathrm{I}}}$ の影響の少ない高負荷速度領域 の実験値をあとめて示してある.これらの図で中型試 験片の実験結果を結ぶ直線を $F_{m}(x)$ として用い, 式 (4)によって $F_{l}(x)$ を計算すると点線のようになる. 同図から分るように，大型試験片の実験結果は $K_{\mathrm{I} c}$ の 值が大さい場合には計算値と一致し， $K_{\mathrm{Ic}}$ が小さいほ ぞ計算值よりも大きい: 下限值付近では大型試験片の

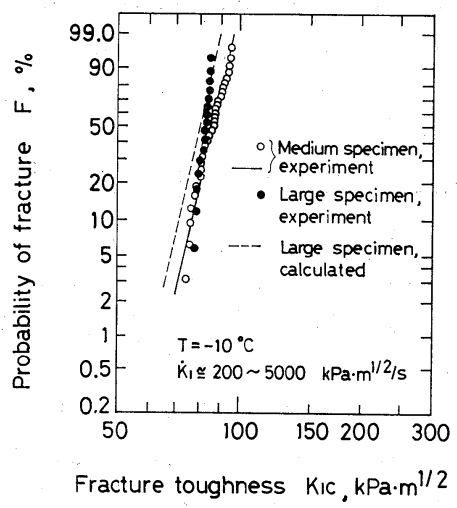

Fig. 6. Comparison of the calculated Weibull distribution of $K_{\text {I } c}$ of large specimens with the test results; calculation from the data of medium size specimens, based on the "weakest link theory".

方が幾分大きくなる傾向が見られる.

このような計算値と実験值とのくい違いが生じた理 由は, 水試験片の破壊のメカニズムがまだよく分らな い現時点では明確ではない，ただ，前述のき裂発生に ついてのレプリカの調査および曲げ試験中の観察の結 果からみると, とくに大型試験片の場合, 最弱欠陥で 発生したき裂が必ずしも急速に全断面の破壊につなが るとは限らないようであって, この点からみても, 今 の場合, 最弱リンク説はそのすまでは適用し難い。

\section{$3 \cdot 4$ 従来の実験值との比較}

Fig. 7 は従来の報告に見られる実験值を浦辺らがま とめたものを再整理し, 本報の結果と対比したもので ある. 混雑を避けるために, 平均值の反を示したが, 各データとも特に低負荷速度になる湾どばらつきが大 きい，たとえば, Liu らの場合, $T=-8^{\circ} \mathrm{C}, \dot{K}_{\mathrm{I}}=2.4$ $\mathrm{kPam}^{1 / 2} / \mathrm{s}$ の点での $K_{\mathrm{Ic}}$ の最大值は約 $300 \mathrm{kPam}^{1 / 2}$, 最小值は約 $110 \mathrm{kPam}^{1 / 2}$ である. $\dot{K}_{\mathrm{I}}$ が $100 \mathrm{kPam}^{1 / 2} / \mathrm{s}$ を越す領域でのばらつきは報告炕よってまちまちであ り, 詳細は省略する.

同図の実験点を結ぶ線は筆者らが実験値の傾向を見

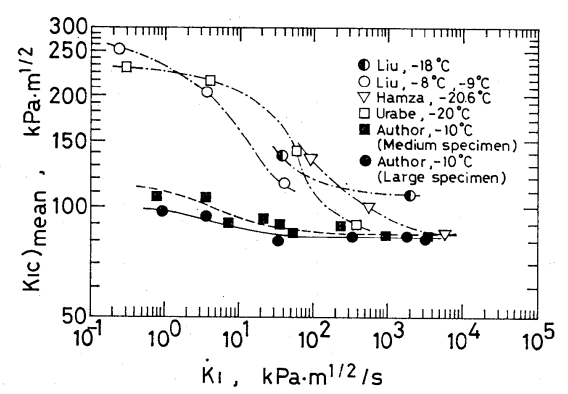

Fig. 7. Comparison of the present data with other reports; chain lines connecting the plots are drawn by the present authors. 
るために画いたものである、結び方に筆者らの主観が 入っているかもしれないが，従来の報告での実験はい ずれも，“低負荷速度領域十遷移領域”もしくは“遷 移領域十高負荷速度領域”で行われているようである. なお， $\dot{K}_{\mathrm{I}}$ が $\fallingdotseq 10000 \mathrm{kPam}^{1 / 2} / \mathrm{s}$ より大さい場合， $K_{\mathrm{I} c}$ が急激に下がっているデータもあるが，本図では 除外した. 同図を見た場合とくに顕著なのは低負荷速 度領域での $K_{\mathrm{I}_{c}}$ の值についての本報と他報告との数值 の差である.それぞれの研究は実験条件が少しずつ異 なっており，このよらな差が出た原因についての判断 は慎重を要する．氷の $K_{\mathrm{I}}$ への影響因子として例觉ば, 試験片の切欠き先端の加工力法, リガメント幅も含め た試験片寸法, その他どちらかといらと, 比較的把握 しやすい事項もあるが，それ以外に，理由は明りょう ではないが氷の凍結速度が $K_{\mathrm{I} c}$ に大きな影響を与え るといら例も報告されており，いずれにせよ，今後の 検討が必要である.

\section{4 結言}

前報で用いた承は粗大結晶のものが多く，また断面 寸法が $25 \times 25 \mathrm{~mm}$ (小型) 执よび $50 \times 50 \mathrm{~mm}$ (中型) 試験片の破壞じん性について報告した.今回は柱状結 晶氷について，断面寸法 $50 \times 50 \mathrm{~mm}$ (中型）和よび $200 \times 50 \mathrm{~mm}$ (大型）試験片を用いて負荷速度および 試験片寸法が破壊じん性に及ぼす影響を調べた結果, 次のような知見を得た。

(1) 前報での放置凍結水の場合 と同じく, $\dot{K}_{\mathrm{I}} \fallingdotseq 10$ $\sim 100 \mathrm{kPam}^{1 / 2} / \mathrm{s}$ 付近に $K_{\mathrm{I}}$ の急変する遷移領域が存在 する.この領域より大きな $\dot{K}_{\mathrm{I}}$ では実験の範囲で $K_{\mathrm{I} c}$ に対る $\dot{K}_{\mathrm{I}}$ の影響は少ない. また全領域を通じて $K_{\mathrm{I} c}$ の最小値に対する $\dot{K}_{\mathrm{I}}$ の影響は少ない。

（2）中型試験片にくらべて大型試験片のばらつきは 約 1/2 と大幅に減少した. しかし， $\dot{K}_{\mathrm{I}} \fallingdotseq 200 〜 5000$ $\mathrm{kPam}^{1 / 2} / \mathrm{s}$ の範囲での検討例で, $K_{\mathrm{I}}$ の值の低下の程 度は単なる最弱リンク説に基づく予想值より少なかっ
た. な就, 大型試験片の $K_{\mathrm{I} c}$ の下限值は中型試験片の 下限値とくらべた場合, 低負荷速度領域ではほぼ一致 し，高負荷速度領域では幾分上昇した.

(3) レプリカ上での観察によると中型試験片のき裂 の出発点は一個が普通であり，大型試験片ではこれが 複数個となっている。き裂の伝ぱのメカニズムはまだ よく分からないが，大型試験片の $K_{I_{c}}$ の低下が最弱リ ンク説の予想值より小さいことと関連が深いものと考 学らる、

最後に, 本研究の実施に当って多くのご援助とご討 議を頂いた北九州工業高等専門学校長（当時, 長崎大 学工学部長) 真武友一先生, 当学, 今井康文教授, ご 支援頂いた（株）アドバンス開発研究所，安藤司文博 士に厚くお礼申し上げる.また熱心に研究に協力され た本学, 内田 武, 梶 聖悟の両君ならびに学生諸君 に心から謝意を表する次第である.

（昭和60年 6 月26日 第 3 回破滖力学シンポジウムにて講演）

\section{参 考 文 献}

1) H. W. Liu and K. J. Miller, J. Glaciology, 22, 135 (1979).

2) D. J. Goodman, "Physics and Mechanics of Ice", ed. by P. Tryde, p. 129 (1979) Springer-Verlag.

3) H. Hamza and D. B. Muggeridge, POAC. 1, 697 (1979).

4）浦辺浪夫，鉄と鋼， 67, 908 (1981).

5) 楠本 韶, 木村宣夫, 内田 武, 高瀬 徹, 材料, 35, 659 (1986).

6) H. Higuchi, Acta Metallurgica, 6, 636 (1958).

7) 岡村弘之, “線形破壊力学入門”, p. 218 (1976) 培風館.

8）石田 誠，“き裂の弾性解析之応力拡大係数”, p. 179 (1978) 培風館.

9）岡村弘之, 板垣 浩, “強度の統計的取扱い”, p. 137 (1976）培風館. 